\title{
RUDOLF MALTER E O PESSIMISMO CRÍTICO SCHOPENHAUERIANO
}

RUDOLF MALTER AND THE CRITICAL SCHOPENHAUERIAN PESSIMISM

\author{
FELIPE DURANTE ${ }^{1}$ \\ Universidade Federal do Espírito Santo (UFES) - Brasil \\ xfelipedurantex@gmail.com
}

\begin{abstract}
RESUMO: Este artigo tem por objetivo, a partir da leitura do célebre livro de Rudolf Malter - $O$ pensamento único: introdução à filosofia de Arthur Schopenhauer (Der Eine Gedanke: Hinführung zur Philosophie Arthur Schopenhauers), em especial da seção intitulada Característica conclusiva: Pessimismo - um conceito crítico (Abschließende Charakteristik: Pessimismus - ein kritischer Begriff ) -, apresentar a hipótese hermenêutica de um dos mais eminentes intérpretes da filosofia schopenhaueriana, a qual versa sobre o pessimismo enquanto conceito crítico, e que pode ser entendida como um dos pontos de sustentação para a justificativa de interpretação da filosofia schopenhaueriana a partir de um viés soteriológico.
\end{abstract}

PALAVRAS-CHAVE: Arthur Schopenhauer. Rudolf Malter. Pessimismo crítico.

ABSTRACT: This article aims to show, based on the reading of the famous book Der Eine Gedanke: Hinführung zur Philosophie Arthur Schopenhauers, especially the section Abschließende Charakteristik: Pessimismus - ein kritischer Begriff, the hermeneutic hypothesis of one of the most important interpreters of Schopenhauer's philosophy, Rudolf Malter. The author deals with the pessimism as a critical concept. The critical pessimism can be understood as one good reason to justify calling the Schopenhauerian philosophy a soteriology

KEYWORDS: Arthur Schopenhauer. Rudolf Malter. Critical pessimism.

\section{INTRODUÇÃO}

Quando se trata de interpretar a filosofia schopenhaueriana existem livros e artigos produzidos por comentadores que são incontornáveis, tamanha a importância de certas contribuições. No Brasil, os textos da professora Maria Lucia Cacciola e dos professores Jair Lopes Barboza e Oswaldo Giacoia Junior são grandes exemplos; em língua italiana, Domenico Fazio, Franco Volpi, Giuseppe Invernizzi, Sandro Barbera, Sossio Giametta; em língua inglesa, Bryan Magee, Cristopher Janaway, David Cartwright; em francês, Alexis Philonenko, Clément Rosset, Jean Lefranc, Marie-José Pernin; no caso da língua alemã, a lista para um

\footnotetext{
${ }^{1}$ Doutor em Filosofia pela Universidade Estadual de Campinas (UNICAMP). Bolsista PNPD/CAPES - Universidade Federal do Espírito Santo (UFES).
} 
estudo sério e rigoroso poderia ser um tanto mais extensa, dado que ela é a língua na qual Arthur Schopenhauer escreveu e teve sua primeira recepção e apreciação.

Dentre os comentadores em língua alemã podemos ressaltar a contribuição de Rudolf Malter (1937-1994)². Professor na Johannes Gutenberg-Universität Mainz e presidente da Schopenhauer-Gesellschaft entre 1985 e 1992, ele é conhecido principalmente pelo sério trabalho empreendido nas pesquisas sobre Immanuel Kant e Arthur Schopenhauer, tendo publicado livros e artigos que se consolidaram como clássicos da interpretação de ambos os filósofos, o que permite a afirmação de que ele foi um dos grandes responsáveis pela renovação do interesse do mundo acadêmico pela filosofia schopenhaueriana. Contudo, ainda não podemos considerar sua produção intelectual estritamente incontornável para pesquisa schopenhaueriana no Brasil, seja pela falta de traduções dessas obras para a língua portuguesa - e até mesmo para outras línguas, como a inglesa -, seja pela dificuldade de encontrar os seus textos em terras tupiniquins.

Na última seção da segunda parte de seu livro de 1988, Der eine Gedanke: Hinführung zur Philosophie Arthur Schopenhauers (O pensamento único: introdução à filosofia de Arthur Schopenhauer) intitulada Abschließende Charakteristik: Pessimismus - ein kritischer Begriff (Característica conclusiva: Pessimismo - um conceito crítico), Malter analisa o conceito de pessimismo para além de seu sentido mais trivial - a disposição em sempre esperar o pior e sempre julgar as coisas pela perspectiva menos favorável -, expondo a sua função sistemática e sua importância para a constituição da filosofia de Arthur Schopenhauer.

Este pequeno artigo tem a modesta pretensão de apresentar - a partir de uma das principais teses de Rudolf Malter, a saber, de que a mais importante obra de Arthur Schopenhauer, O Mundo como Vontade e Representação, é uma comunicação da possibilidade da libertação da humanidade da dor da existência através da negação da vontade (Cf. FAZIO; KOßLER; LÜTKEHAUS, 2009, p. 209; MALTER, 1991 e 2010) - os principais pontos desenvolvidos na argumentação do comentador em tal capítulo da referida obra, como forma de clarificar uma tese que, por ser canônica, muitas vezes é reproduzida em textos de comentadores de forma indireta. O segundo objetivo envolvido é o de entender as implicações decorrentes da caracterização do chamado pessimismo schopenhaueriano enquanto pessimismo crítico. Talvez a maior delas seja a possibilidade de interpretar a filosofia do autor de forma a afastá-la de uma caracterização meramente niilista, ${ }^{3}$ apresentando-a como uma teoria da libertação, e, portanto, possibilitando a sua tipificação como uma teoria da salvação, i.e., possibilitando o entendimento da filosofia schopenhaueriana como uma soteriologia.

\footnotetext{
${ }^{2}$ Podemos destacar dois de seus livros como grandes contribuições: Cf. MALTER, 1991 e 2010.

${ }^{3}$ Em acepção ampla, niilismo pode ser entendido, nesse contexto hermenêutico, como uma postura filosófica e existencial de descrença generalizada, a qual acaba por se constituir enquanto valoração negativa da vida e da existência, devido à falta de uma significação e sentido últimos do mundo. Sobre o conceito de Niilismo (Nihilismus) na história da filosofia cf. o verbete "Nihilismus" em GOERD; MÜLLER-LAUTER, 1971-2007.Sobre o niilismo especificamente da filosofia schopenhaueriana Cf. RODRIGUES, 2015, e SALVIANO, 2005.
} 


\section{O CONCEITO DE PESSIMISMO CRÍTICO SCHOPENHAUERIANO SEGUNDO RUDOLF MALTER} EM SEU LIVRO DER EINE GEDANKE

Quando a filosofia schopenhaueriana é associada ao pessimismo, em geral, isso é feito a partir da "avaliação negativa da existência individual e do mundo em geral [...], uma avaliação sintetizada na fórmula segundo a qual o não ser é preferível ao ser" (FAZIO; KOßLER; LÜTKEHAUS, 2009, p. 209). O termo pessimismo (Pessimismus) é grafado apenas oito vezes na obra de Schopenhauer (Cf. DEBONA, 2013, p. 20), mas apenas em quatro ocorrências o termo se refere ao pessimismo do próprio autor, sendo duas delas em seus manuscritos ${ }^{4}$ e as outras duas em sua correspondência. Tais referências encontram-se nas seguintes passagens da obra do filósofo: (i) no fragmento póstumo 66 dos Adversaria de 1828 (Cf. SCHOPENHAUER, 1985, HN Bd III, Adversaria, p. 464); (ii) no fragmento póstumo 49 dos Pandectae II de 1833, (Cf. SCHOPENHAUER, 1985, HN Bd IV (1), Pandectae II, p. 160); (iii) na carta de 15 de julho de 1855 a Julius Frauenstädt (Cf. SCHOPENHAUER, 1911-1942b, 558, XV, p. 393); ${ }^{5}$ e (iv) na carta de 16 de julho de 1860 a David Asher, na qual Schopenhauer não analisa conceitualmente o pessimismo, apenas relata $\mathrm{O}$ isolamento em que se encontra e menciona argumentos ad hominem em benefício de seu pessimismo (Cf. SCHOPENHAUER, 1911-1942b, 809, XV, p. 821). ${ }^{6}$ Ou seja, nenhuma dessas ocorrências do termo é constatada nos escritos publicados do filósofo.

Segundo Malter, o primeiro passo para melhor compreensão da questão proposta é justamente precisar o significado e a função do termo pessimismo empregado na filosofia schopenhaueriana, a fim de nos desfazermos do erro de apresentar o filósofo apenas como um queixoso do mundo que, por razões individuais e biográficas, enxerga o mundo de forma cinza e depressiva (Cf. MALTER, 2010, p. 102). A filosofia schopenhaueriana pode ser denominada pessimista apenas se pessimismo for entendido como um conceito crítico a partir de um duplo ponto de vista formal, os quais Malter apresenta da seguinte maneira:

1. O conceito de "Pessimismo" destaca-se como um tipo de entendimento do mundo empírico dado a partir de um outro tipo de entendimento (o qual - como ainda será mostrado - é designado de um lado como eudemonismo, e, de outro, como otimismo). Pessimismo é um modo no qual a razão reflexiva se volta à experiência da dor. 2. O conceito de "pessimismo" indica o tipo exato da compreensão racional dessa experiência, os outros dois termos referem-se ao falso tipo de compreensão racional da existência da dor. Pessimismo é, portanto, um conceito valorativo:

\footnotetext{
${ }^{4}$ Para leitura dos Manuscritos Póstumos de Schopenhauer utilizamos a clássica e bem conhecida edição Der handschriftliche Nachlaß in fünf Bänden, organizada por Arthur Hübscher, cuja referência completa se encontra nas Refrências bibliográficas.

${ }^{5}$ A citação indica o número da correspondência, tomo e página.

6 "Sim, sim! Todo mundo, de tempos em tempos, recebe a favor do meu pessimismo um argumentum ad hominem, o qual também possui o melhor dele”. No original alemão: „Ja, ja! Jeder erhält von Zeit zu Zeit so ein argumentum ad hominem zu Gunsten meines Pessimismus, - der also das Beste davon hat".
} 
ele fala a partir das compreensões corretas e falsas da experiência concretamente dada ao ser humano. (MALTER, 2010, p. 103). ${ }^{7}$

O pessimismo pode, assim, a partir desse duplo ponto de vista formal, ser entendido como a exata identificação do valor da existência humana (Cf. MALTER, 2010, p. 103). Malter torna ainda mais exata a forma pela qual ele entende o significado de pessimismo na filosofia de Schopenhauer: segundo o comentador, em geral, o julgar de maneira pessimista o mundo e, em particular, a existência humana significa julgar ambos como possuidores de uma tendência ao não ser (Cf. MALTER, 2010, p. 103). Esse juízo é alcançado pela razão reflexiva apenas através da facticidade/concretude (Faktizität) da dor, mas tal facticidade/concretude só é possível sob o domínio do princípio de razão suficiente (Cf. MALTER, 2010, p. 103), i.e., é apenas espaço-temporalmente, inserido em uma relação de causa e consequência, que é possível a facticidade/concretude da dor. O pessimismo, tomado como juízo sobre a dor da existência, constitui-se, por isso, como um juízo sobre o ser e sua finitude no tempo, finitude esta que consiste na constante ameaça do ser vir-a-ser um não-ser (Cf. MALTER, 2010, p. 104). Ser ameaçado pelo nãoser é o indicador (Index) do fato de que, embora seja, o ser não deveria ser. E que esse não-dever-ser indica também que em cada ser submetido ao princípio de razão encontra-se o caráter da culpa (Charakter der Schuld). Assim, o comentador pode defender a posição de que, tomado de forma abstrata em geral, o pessimismo é a visão do caráter de culpa e da nulidade a serem superados pelos seres submetidos ao princípio de razão (Cf. MALTER, 2010, p. 104) - superação essa que envolve necessariamente o ultrapassamento de tal princípio.

Malter localiza na obra de Schopenhauer dois pontos fundamentais nos quais, segundo ele, é indicada claramente a função crítica do conceito de pessimismo:

[...] o primeiro [ponto] na avaliação da ânsia individual à satisfação através da existência afirmadora da vontade regida pelo princípio de razão; o segundo [ponto] na avaliação do mundo dado em geral, enquanto esse é elevado a produto de um criador sábio e bom. No primeiro caso, o pessimismo é uma crítica do eudemonismo, no segundo, crítica do otimismo (que deriva de um pensamento teodicéico). (MALTER, 2010, p. 105). ${ }^{8}$

\footnotetext{
7 No original alemão: „1. Der Begriff „Pessimismus" hebt sich als eine Art des Verstehens der empirisch gegebenen Welt von einer anderen Art des Verstehens ab (die- wie noch ausgeführt werden wird- zum einen als Eudämonismus, zum anderen als Optimismus zu kennzeichnen ist). Pessimismus ist eine Weise, in welcher sich die reflektierende Vernunft der Leidenserfahrung zuwendet. 2. Der Begriff „Pessimismus“ nennt die richtige Art des vernünftigen Begreifens dieser Erfahrung, die beiden anderen Termini beziehen sich auf die falsche Art des vernünftigen Begreifens der Leidensexistenz. Pessimismus ist demnach ein wertender Begriff: er redet von richtigem und falschem Begreifen der konkret dem Menschen gegebenen Erfahrung."

${ }^{8}$ No original alemão: „[...] zum einen in der Beurteilung des individuellen Strebens nach Erfüllung in der durch den Satz vom Grund beherrschten willensbejahenden Existenz, zum anderen in der Beurteilung der gegebenen Welt im ganzen, insofern diese zum Produkt eines weisen und gütigen Schöpfers erhoben wird. Im ersten Fall ist Pessimismus Eudämonismuskritik, im zweiten Fall Kritik des Optimismus (der aus dem Theodizeedenken hervorgeht)."
} 
Tomando a afirmação expressa no segundo tomo d'O Mundo como Vontade e Representação de que a busca pela felicidade é o único erro inato do ser humano (Cf. SCHOPENHAUER, 1911-1942a, WWV II, p. 729), Malter estabelece uma relação identitária entre a vontade auto afirmar-se e a busca pela felicidade.

A busca pela felicidade resulta na experiência continua da fragilidade de cada momento, seja no curto intervalo de prazer que se torna rapidamente tédio, seja na esperança do querer ser satisfeito e de sua frustração, ou, ainda, na desilusão do querer não satisfeito. Nesse contexto, o pessimismo, tomado como postura de vida, ganha o papel de um corretivo da existência (Der Pessimismus als Lebenshaltung gewinnt so die Rolle des Korrektivs) (Cf. MALTER, 2010, p. 105). Assim, nas palavras de Malter:

Uma vez que o pessimismo é uma atitude teórica e prática originada na reflexão racional e fundada na experiência concreta experiência da dor - perante à existência determinada pelo princípio de razão, e uma vez que a forma explícita de uma tal reflexão abstrata fundada na experiência é a filosofia, o pessimismo é a postura genuinamente filosófica frente à existência temporal (MALTER, 2010, p. 105-106). ${ }^{9}$

Nesse ponto o pessimismo pode ser entendido como conceito crítico na medida em que exerce uma crítica ao eudemonismo, i.e., o pessimismo é entendido como posição que enuncia que a felicidade não é a finalidade da existência dos indivíduos, o que acaba por engendrar uma visão de mundo que pode ser chamada de realista e desencantada (FAZIO; KOßLER; LÜTKEHAUS; 2009, p. 210), mas não pessimista no sentido comumente associado ao conceito. Ele seria o conhecimento de que, eliminando as falsas esperanças e expectativas sobre a vida e sobre o mundo, seria possível desenvolver a consciência capaz de transformar o querer em não querer, a voluntas em nolutas, como aponta claramente o professor Fazio:

O pessimismo enquanto conceito crítico é exatamente aquele conhecimento de que, eliminando toda ilusão sobre a vida e sobre o mundo, é capaz de gerar a consciência da necessidade de transformar a voluntas em noluntas. (FAZIO; KOßLER; LÜTKEHAUS, 2009, p. 209). ${ }^{10}$

Rudolf Malter, prosseguindo na derivação das consequências de sua definição de que o pessimismo é um conceito crítico, acaba por chegar ao ponto em que ele deve considerar, em consonância com todo o exposto de modo exaustivo por Schopenhauer em sua obra, a impossibilidade de se alcançar uma satisfação (Erfüllung) da afirmação da vontade no espaço-tempo, i.e., a

\footnotetext{
9 No original alemão: „Da Pessimismus eine aus vernünftiger Überlegung entstehende, auf der konkreten Leidenserfahrung aufruhende theoretische und praktische Haltung zum Satz-vom-Grund bestimmten Dasein ist, und da die explizite Form einer solchen erfahrungsfundierten abstrakten Reflexion die Philosophie ist, ist Pessimismus die genuin philosophische Haltung gegenüber der zeitlichen Existenz."

${ }^{10}$ No original italiano: "il pessimismo, in quanto concetto critico, è appunto quella conoscenza che, spazzando via ogni illusione sulla vita e sul mondo, è in grado di generare la consapevolezza della necessità di trasformare la voluntas in noluntas".
} 
impossibilidade de uma solução definitiva para o sofrimento no mundo enquanto se está submetido ao princípio de razão, enquanto se está no plano representacional. ${ }^{11} \mathrm{O}$ pessimismo da felicidade (Glücks-Pessimismus) implica no reconhecimento da dor da existência como a forma de existência efetiva e da fragilidade da existência em meio a essência de dor, em contraposição à expectativa de ausência de dor e à satisfação dos sentidos (Cf. MALTER, 2010, p. 108-109).

Ao expor todos os martírios deste mundo para alguém - Malter ilustra essa passagem com exemplos que podem ser encontrados nos diários de viagem de Schopenhauer, nos quais o filósofo descrevera a própria experiência de observação da miséria do mundo por ocasião de sua viagem pela Europa quando ainda jovem (Cf. SCHOPENHAUER, 1988), mas o exegeta poderia ter utilizado tranquilamente qualquer um dos vários exemplos empregados pelo filósofo ao longo da sua obra publicada - o comentador crê no desmonte da tese leibniziana do melhor dos mundos possíveis: diante da experiência mais elementar da nulidade - da insignificância - da existência individual, seria incompreensível sustentar qualquer otimismo.

Assim, Malter pode caracterizar o pessimismo como critério constituído enquanto crítica ao otimismo que brota da teodiceia, e isso significa uma crítica da justificativa da existência da dor como resultado de um fim superior transcendente, i.e., o pessimismo crítico schopenhaueriano funciona como uma crítica à ideia de mundo como obra de um Deus criador bom e providente.

A argumentação de Malter acaba por abrir caminho para duas importantes consequências: (i) a forte contraposição entre o teísmo e o pessimismo - que se tornam, assim, para ele, termos antitéticos, i.e., termos que não podem coexistir (Cf. MALTER, 2010, p. 112-114), dado que, segundo o comentador, uma justificativa do mal do mundo estaria fora de questão para o pessimismo, justamente o que o teísmo faz - justifica o mal no mundo; e (ii) consolida-se dessa forma uma das marcas de sua interpretação sobre a filosofia schopenhaueriana: o seu traço soteriolológico, o qual exprime que a redenção (Erlösung) só pode ser alcançada por aqueles poucos eleitos que atingem a negação da vontade, i.e., da salvação ser obtida para além das amarras do princípio de razão. A questão que ainda resta explicitar é, então, a seguinte: como o pessimismo pode ser entendido e articulado enquanto elemento possibilitador da salvação?

A avaliação pessimista da dor, ou seja, na argumentação do comentador, o fato de a dor, o sofrimento, e as intempéries não poderem ser justificáveis com base ou apelo à alguma justiça divina, não implica a afirmação da sua falta de sentido. Dito em outras palavras, a partir da avaliação pessimista da dor da existência dada, não se segue a sua falta de sentido e isso significa que não se

$11 \mathrm{Na}$ obra Aphorismen zur Lebensweisheit (Aforismos para Sabedoria de Vida), a qual Schopenhauer define como um desvio / desprendimento / afastamento (abgehen) e acomodação (Akkommodation) de seu sistema, encontramos a ciência da incapacidade de resolução do problema do sofrimento e da dor da existência no plano representacional, mas também a possibilidade de reduzi-los onde possível. 
recai no niilismo; ${ }^{12}$ significa exatamente o seu contrário: é precisamente com esta avaliação - a avaliação da dor da existência dada - que o pessimismo se mostra como um meio de instrumentalizar o fato / a concretude da dor e permite que o indivíduo agraciado ${ }^{13}$ seja capaz de chegar à negação da vontade. A dor tem um sentido e esse sentido consiste no afastar o indivíduo cheio de impulsos vitais da afirmação da vida e, por consequência, dada a identidade entre afirmação da vontade e sofrimento, da própria dor.

O olhar pessimista sobre a dor transforma-a em meio de sua própria superação. O pessimismo crítico, para Malter, é a chave para a interpretação da dor em um sentido que ela possa gerar uma consciência quietista. Isso permite afirmar que uma vez que a dor e o sofrimento são apresentados como a segunda via de salvação, conforme textualmente exposto no $\$ 68$ de $M V R$ e em seus suplementos - no capítulo 49 intitulado A Ordem da Salvação (Die Heilsordnung) -, no sentido proposto por Malter, o pessimismo pode ser libertador, como uma via de salvação, através justamente da tomada de consciência da dor.

A proposta de interpretação do pessimismo como conceito crítico apresenta, assim, duas dimensões centrais para o entendimento das consequências que ele produz nesse modo de interpretar a filosofia schopenhaueriana: (i) a perspectiva teórica, na qual o pessimismo assume uma reflexão racional que permite a tomada de consciência da dor, e (ii) a perspectiva concreta, que se refere à experiência concreta do fato da dor. Ambas as perspectivas permitem (a) o afastamento da justificativa do mal do mundo fundamentada em uma teodiceia, (b) o afastamento da busca da felicidade como finalidade do indivíduo, e, portanto, a recusa de um eudemonismo, e, por fim, (c) a caracterização da filosofia schopenhaueriana como uma teoria da salvação.

O pessimismo enquanto conceito crítico, conforme apresentado, é interpretado por Malter como uma das chaves para o quietismo e para a redenção, o que torna lícito, desse modo, a caracterização da filosofia schopenhaueriana como uma filosofia soteriológica, tese amplamente difundida e assumida - de modo consciente ou de forma indireta - por grande parte daqueles que se debruçam sobre a obra do filósofo da vontade.

\section{REFERÊNCIAS BIBLIOGRÁFICAS}

DEBONA, Vilmar. A outra face do pessimismo: entre radicalidade ascética e sabedoria de vida. Tese (Doutorado em Filosofia) - Universidade de São Paulo, São Paulo, 2013.

\footnotetext{
${ }^{12}$ Aqui fica claro que, para Malter, o pessimismo deve ser interpretado em chave crítica: caso o pessimismo fosse entendido no sentido mais trivial e recorrente - como apontado acima, enquanto disposição em sempre esperar o pior e sempre julgar as coisas pela perspectiva menos favorável ele facilmente conduziria ao niilismo. Exatamente por ser entendido enquanto conceito crítico, ele enseja a possibilidade de interpretação da filosofia schopenhaueriana enquanto uma soteriologia, afastando-se, portanto, de uma caracterização niilista.

${ }^{13}$ Sobre a questão da graça (Gnade) em Schopenhauer Cf. o $\$ 70$ de $M V R$. Sobre o conceito de graça (Gnade) na história da filosofia cf. o verbete "Gnade" em PETERS, 1971-2007.
} 
FAZIO, Domenico. A Escola de Schopenhauer. In: CARVALHO, Ruy; COSTA, Gustavo; MOTA, Thiago. (Orgs.) Nietzsche - Schopenhauer: Metafísica e Significação Moral do Mundo, volume II. Fortaleza: EdUECE, 2014. pp. 11-36.

FAZIO, Domenico; KOßLER, Matthias; LÜTKEHAUS, Ludger. (Orgs.). La Scuola di Schopenhauer: Testi e contesti. A cura del Centro interdipartimentale di ricerca su Arthur Schopenhauer e la sua scuola. In: Schopenhaueriana - Collana del Centro interdipartimentale di ricerca su Arthur Schopenhauer e la sua scuola dell'Università del Salento diretta da Domenico M. Fazio, Matthias Koßler e Ludger Lütkehaus, Vol. 2. Lecce: Pensa Multimedia, 2009.

GOERD, Wilhelm; MÜLLER-LAUTER, Wolfgang. Nihilismus. In: GABRIEL, Gottfried; GRÜNDER, Karlfried; RITTER, Joachim. Historisches Wörterbuch der Philosophie. Vollig neubearbeitete Ausg. des Worterbuchs der philosophischen Begriffe von Rudolf Eisler, v. 6. Basel: Schwabe, 1971-2007. p. 846-854.

INVERNIZZI, Giuseppe. Il pessimismo tedesco dell'Ottocento: Schopenhauer, Hartmann, Bahnsen e Mainländer e i loro avversari. Firenze: La Nuova Italia, 1994.

MALTER, Rudolf. Arthur Schopenhauer Tranzendentalphilosophie und Metaphysik des Willens. Stuttgart-Bad Cannstatt: Fromman-Holzboog, 1991.

Der Eine Gedanke: Hinführung zur Philosophie Arthur Schopenhauers. Darmstadt: Wiss. Buchges., 2010.

PETERS, Albrecht. Gnade. In: GABRIEL, Gottfried; GRÜNDER, Karlfried; RITTER, Joachim. Historisches Wörterbuch der Philosophie. Vollig neubearbeitete Ausg. des Worterbuchs der philosophischen Begriffe von Rudolf Eisler, v. 3. Basel: Schwabe, 1971-2007. p. 707-713.

RODRIGUES, Eli. Niilismo, ressentimento e patologia: a filosofia de Schopenhauer como sintoma da decadência cultural europeia segundo a crítica de Friedrich Nietzsche. Revista Opinião Filosófica, Porto Alegre, v. 6; n. 02, 2015.

SALVIANO, Jarlee. Desconfortável consolo: a ética niilista de Arthur Schopenhauer. Cadernos de Ética e Filosofia Política, Universidade de São Paulo, v. 6, p. 83-109, $1 / 2005$.

SCHOPENHAUER, Arthur. Arthur Schopenhauers sämtliche Werke. Hrsg. Von Paul Deussen. Munique: R. Piper, 1911-1942a.

Der Briefwechsel. In: Arthur Schopenhauers sämtliche Werke 14., 15. und 16. Band Ergänzungen um neu Aufgefundenes aus den Jahrbüchern der Schopenhauergesellschaft u. Arthur Schopenhauer Gesammelte Briefe hrsg. von Paul Deussen. München: R. Piper, 1911-1942b.

Der handschriftliche Nachlaß in fünf Bänden. Vollständige Ausgabe in sechs Teilbänden. Herausgegeben von Arthur Hübscher. Band 1: Frühe Manuskripte (1804 - 1818). - Band 2: Kritische Auseinandersetzungen (1809 - 1818). - Band 3: Berliner Manuskripte (1818 - 1830). - Band 4, I: Die Manuskriptbücher der Jahre 1830 - 1852. - Band 4, II: Letzte Manuskripte. Gracians Handorakel. Band 5: Randschriften zu Büchern. - 5 Bände in 6 Bänden (vollständig). (= dtv klassik). München: Deutscher Taschenbuch Verlag, 1985. 
Die Reisetagebücher von Arthur Schopenhauer. Hrsg. von Ludger Lütkehaus. Zürich: Haffmans, 1988.

Recebido em: 17-07-2017

Aceito para publicação em: 02-11-18 